\title{
How to Improve the Accuracy of the Initial Evaluation, Using a System Developed By Johns Hopkins Hospital Doctors
}

\author{
Nelson Hendler* \\ Johns Hopkins University School of Medicine, USA \\ *Corresponding author: Nelson Hendler, Former assistant professor of neurosurgery, Johns Hopkins University School of Medicine, USA

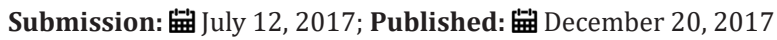

\section{Editorial}

Researchers from Johns Hopkins Hospital have published information which reports:

A. $40 \%-80 \%$ of chronic pain patients are misdiagnosed [1-5]. Most are told they have sprains and strains when they actually have surgically correctable lesions [1,2,5]. For CRPS (RSD) 71\%$80 \%$ of patients really have nerve entrapment, which responded to peripheral nerve decompression $[3,4]$.

B. Doctors order the wrong tests and don't spend enough time taking a careful history. A Wall Street Journal article quotes medical research which says the two leading causes of misdiagnosis are

a. Ordering the wrong diagnostic test (57\%)

b. Poor history taking (56\%) [6].

C. MRIs miss damaged discs $76 \%-78 \%$ of the time, and CTs miss bony lesions detected by 3D-CT $56 \%$ of the time $[7,8]$. The tests used at Johns Hopkins Hospital are flexion-extension X-rays with odontoid views, 3D-CT, bone scan, provocative disco grams, facet blocks, root blocks, and peripheral nerve blocks which, for the most part, are physiological tests rather than anatomical tests [5].

D. Many articles in the medical literature emphasize the importance of a careful history $[9,10]$.

E. Physicians interrupted patients an average of 12 seconds after the resident entered the room. One fourth of the time, physicians interrupted patients before they finished speaking. Physicians averaged interrupting patients twice during a visit [11].

F. The physician time with patients averaged 11 minutes, with the patient speaking for about 4 minutes [11].

Another study reported that a physician spent 10.7 minutes in face to face contact with a patient [12]. To combat the poor history taking techniques demonstrated by most physicians, a team of physicians from Johns Hopkins Hospital developed an Internet based questionnaire, which duplicates a physician taking a careful and thorough history. The questionnaire consists of 72 questions, with 2008 possible answers, which takes 45-60 minutes for a patient to complete. The questionnaire, called the Diagnostic Paradigm, which is available in either English or Spanish, asks all the questions a competent and concerned physician would ask, if the physician spent an hour taking a careful history. When the patient finishes the Diagnostic Paradigm, the answers to the questions are scored, using a propriety scoring algorithm. Then, within five minutes of the completion of the Diagnostic Paradigm, diagnoses are generated, based on the answers to the questions. These diagnoses have a $96 \%$ correlation with diagnoses of Johns Hopkins Hospital doctors [13]. Then, based on the correct diagnosis, the Treatment Algorithm recommends the correct test to use. The efficacy of this technique has been documented by the ability of the Diagnostic Paradigm and Treatment Algorithm to predict intraoperative finding with $100 \%$ accuracy [14].

The tests are available at www.MarylandClinicalDiagnostics. com, and can improve patient care. These tests benefit the physician and patient in various ways:

a. Produce a more accurate evaluation in less time, with less inter-rater reliability issues.

b. Get paid for the actual tests them, using CPT codes which have been used in the past.

c. See more patients in a day, since using the tests will allow a physician to evaluate a patient in 5 minutes instead of the normal 11-15 minutes.

d. The Treatment Algorithm will recommend that a physician perform facet blocks, root blocks, peripheral nerve blocks, and provocative disco grams at a far higher level than they do now.

\section{References}

1. Hendler N, Kozikowski J (1993) Overlooked physical diagnoses in chronic pain patients involved in litigation. Psychosomatics 34(6): 494450 .

2. Hendler N, Bergson, C Morrison C (1996) Overlooked physical diagnoses in chronic pain patients in litigation, Part 2. Psychosomatics 37(6): 509517.

3. Hendler N (2002) Differential diagnosis of complex regional pain syndrome. Pan Arab Journal of Neurosurgery 6(2): 1-9. 
4. Dellon AL, Andronian E, Rosson GD (2009) CRPS of the upper or lower extremity: surgical treatment outcomes. J Brachial Plex Peripher Nerve Inj 4(1): 1.

5. Long D, Davis R, Speed W, Hendler N (2006) A Fusion for occult posttraumatic cervical facet injury. Neurosurg Q 16(3): 129-135.

6. Landro L (2013) The wall street journal.

7. Sandhu HS, Sanchez-Caso LP, Parvataneni HK, Cammisa FP Jr, Girardi FP, Ghelman B, et al. (2000) Association between findings of provocative discography and vertebral endplate signal changes as seen on MRI. J Spinal Disord 13(5): 438-443.

8. Zinreich SJ, Long DM, Davis R, Quinn CB, McAfee PC, Wang H, et al. (1990) Three-dimensional CT imaging in postsurgical "failed back" syndrome. J Comput Assist Tomogr 14(4): 574-580.

9. Wellens HJ, Brugada P (1987) Antiarrhythmic therapy. The value of the history of the patient. Eur Heart J, pp. 71-75.

10. Linzer M, Yang EH, Estes NA 3rd, Wang P, Vorperian VR, Kapoor WN, et al. (1997) Diagnosing syncope. Part 1: Value of history, physical examination, and electrocardiography. Clinical Efficacy Assessment Project of the American College of Physicians. Ann Intern Med 126(12): 989-996.

11. Rhoades DR, McFarland KF, Finch WH, Johnson AO (2001) Speaking and interruptions during primary care office visits. FAM Med 33(7): 528532.

12. Gottschalk A, Flocke S (2005) Time spent in face-to-face patient care and work outside the examination room. Ann FAM Med 3(6): 488-493.

13. Hendler N, Berzoksky C, Davis R J (2007) Comparison of clinical diagnoses versus computerized test diagnoses using the mensana clinic diagnostic paradigm (Expert System) for diagnosing chronic pain in the neck, back and limbs. Pan Arab Journal of Neurosurgery, pp. 8-17.

14. Landi A, Davis R, Hendler N, Tailor A (2016) Diagnoses from an On-Line expert system for chronic pain confirmed by intra-operative findings. Journal of Anesthesia \& Pain Medicine 1(1): 1-7. 